\title{
Fırın Ürünlerinde Kinoa Kullanımı
}

\author{
*Şule KESKIN1 \\ Asuman KAPLAN EVLICE ${ }^{2}$
}

${ }^{1}$ Abant İzzet Baysal Üniversitesi, Mühendislik Mimarlık Fakültesi, Gıda Mühendisliği BI., Bolu

${ }^{2}$ Tarla Bitkileri Merkez Araştırma Enstitüsü Müdürlüğü, Ankara

*Sorumlu yazar e-posta (Corresponding author; e-mail): sulekeskin@ibu.edu.tr

Geliş Tarihi (Received): 20.10.2015～Kabul Tarihi (Accepted): 06.11.2015

\section{Öz}

Orijini Güney Amerika'nın And Dağları olan kinoa (Chenopodium quinoa Willd.) Arjantin, Şili, Bolivya, Peru, Ekvador ve Kolombiya gibi pek çok yerde yetiştirilmektedir. Amerika kıtasından sonra Avrupa ve Asya kıtalarında da yetiştirilmeye başlanmıştır. Genetik çeşitliliği oldukça fazla olan kinoa, yüksek adaptasyon kabiliyetine de sahiptir. Ülkemizde ise son yıllarda tanınmış ve tüketilmeye başlanmıştır. 2013 yılı Birleşmiş Milletler Tarım Örgütü (FAO) tarafından "Uluslararası Kinoa Yılı" olarak ilan edilmiştir. Çeşide bağlı olarak değişmekle birlikte, yaklaşık \% 10 - 18 protein, \% 4.50 - 8.75 yağ, \% 54.1 - 64.2 karbonhidrat, \% 2.40 - 3.65 kül ve \% 2.1 - 4.9 lif içermektedir. Ayrıca, E vitamini, B grubu vitaminler, lisin aminoasidi ve esansiyel yağ asitleri açısından da zengin bir bitkidir. Bu nedenle buğday ununa ilave edildiğinde elde edilen ürünlerin besin değerini artırmaktadır. Ancak kinoanın bileşiminde acılığa sebep olan saponinlerin bulunması ve buğday gluten proteinlerinin eksikliği fırın ürünlerinde kullanımını sınırlandırmaktadır. Yapısında bulunan saponinler uzaklaştırıldıktan sonra, kinoa zenginleştirme amacı ile ekmek, kek, bisküvi gibi fırın ürünlerinin üretiminde tat, aroma, tekstür, görünüş gibi özellikler dikkate alınarak, buğday ununa belli oranlarda katılabilmektedir. Bunun yanı sıra çölyak hastaları için ekmek yapımında kinoa nişasta kaynağı olarak da kullanılabilmektedir. Bu makalede kinoanın çeşitli fırın ürünlerinde kullanımı hakkında bilgiler verilmeye çalışılmıştır.

Anahtar Kelimeler: Kinoa, ekmek, kek, bisküvi

\section{Use of Quinoa in Bakery Products}

\section{Abstract}

Quinoa (Chenopodium quinoa Willd.) originated in the Andean region in South America has been cultivated in many places like Argentina, Chile, Bolivia, Peru, Ecuador and Colombia. After the American continent, it began to be grown in Europe and Asia continents. The quinoa has genetic diversity and also capability of high adaptability. In recent years, it has begun to be known and consumed in our country. Food and Agriculture Organization of the United Nations (FAO) has declared the year 2013 as the "International Year of Quinoa". It contains approximately 10 - $18 \%$ protein, $4.50-8.75 \%$ fat, $54.1-64.2 \%$ carbohydrates, $2.40-3.65 \%$ ash and $2.1-4.9 \%$ fiber depending on variety. Also, it is a good nutritional source of vitamin $E$, group of vitamin $B$, amino acid of lysine and essential fatty acids. Therefore, adding quiona to wheat flour improves the nutritional value of the products obtained. However, in the composition of quinoa, presence of saponins causing bitter taste and lack of wheat gluten proteins are limiting the use it in bakery products. After removing saponins, which are found on the outer layer, quinoa can blend to wheat flour in certain proportions on production of bakery products like bread, cakes, biscuits taking into account characteristics such as taste, aroma, texture appearance with the aim of enriching. Besides, quinoa can be used as a starch source at bread making for celiac patients. In this paper, it is aimed to give information about the use of quinoa at various bakery products.

Keywords: Quinoa, bread, cake, cookie

\section{Giriş}

Kinearat

inoa (Chenopodium quinoa Willd.) kazayağıgiller (Chenopodiaceae) familyasından çift çenekli ve tek yıllık bir bitkidir. Boyu 40-150 $\mathrm{cm}$ arasında değişen bitki, geniş yapraklı ve

kazık köklüdür. Kurağa, soğuğa ve tuza dayanıklı olan kinoa, geniş pH aralığına sahip topraklarda ve deniz seviyesinden 4000 m yüksekliğe kadar olan alanlarda 
yetişebilmektedir (Repo-Carrasco-Valencia and Serna 2011; Tan ve Yöndem 2013; Yıldız et al. 2014).

Bin tane ağırlığı $1.99-5.08 \mathrm{~g}$ arasında değişen (Reichert et al. 1986), yassı ve oval şekilli olan kinoanın tohumları, genellikle açık sarı renkte olup, pembeden siyaha kadar değişim göstermektedir (Karyotis et al. 2003). Tohum rengi kabukta bulunan saponinden kaynaklanmakta olup, embriyo pericarp içerisinde tohumun \% 60'ını oluşturmaktadır (Tan ve Yöndem 2013).

Anavatanı Güney Amerika olan kinoanın, M.Ö. 3000 yılından beri Bolivya ve Peru'da tarımı yapılmaktadır (Lindeboom 2005; Tan ve Yöndem 2013). Avrupa'ya ise ilk olarak 1970'li yıllarda İngiltere üzerinden giriş yapmış ve 1993 yılında Avrupa Birliği tarafından "Quinoa - A multipurpose crop for EC's agricultural diversification" isimli bir proje başlatılmıştır (Jacobsen 2003).

Bolivya, Peru, Ekvador gibi asıl kinoa üretiminin yapıldığı bölgelerde, 1992-2010 yılları arasında üretim alanı ikiye, miktarı ise üçe katlanmıştır (Iglesias-Puig et al. 2015). ABD'de yaklaşık on yıldır çok yaygın olarak tüketilmektedir (Tan ve Yöndem 2013). Ülkemizde ise yeni yeni tanınmaya başlamış ve Peru'dan 2012 yılında 15 ton, 2013 yılında ise yaklaşık 22 ton ithalat yapılıış̧ır (Anonim 2015).

Son yıllarda insan ve hayvan beslenmesi üzerinde yoğun çalışmalar yapılmakta olup, kinoanın dünyadaki açlık sorununa çare olabilecek bitkilerden biri olduğu belirtilmektedir (Ranhotra et al. 1993; Vilehe et al. 2003; Tan ve Yöndem 2013; Yıldız et al. 2014). Birleşmiş Milletler Tarım Örgütü (FAO) tarafından 2013 yılı "Uluslararası Kinoa Yılı" olarak ilan edilmiştir (Iglesias-Puig et al. 2015).

İnsan beslenmesinde, tahıllar ve baklagillerde olduğu gibi kinoanın tohumu da kullanılmaktadır (Yıldız et al. 2014). Bu tohumlar çorbalara ve ekmeklere katılabilmekte, haşlanmış kinoa tohumu ise salatalarda ve yemeklerde kullanılmaktadır. ABD'de çoğunlukla beyaz ve sarı renkli kinoa tohumu tüketilmekte olup, pirinç gibi pilav yapımında kullanılmaktadır. Kinoa unu makarna, krep, ekmek, bisküvi, kek ve kraker yapımında kullanılabilmektedir. Kinoadan "kispina" adı verilen ekmek de yapılmaktadır. Noodle üretiminde $\% \quad 40$ oranında kinoa unu kullanımının görünüş ve diğer özelliklerde değişikliğe neden olmadığı belirtilmiştir. Aynı zamanda kinoadan darı ile fermente edilerek bira benzeri içecekler de üretilmektedir. Bunların dışında kinoa yaprakları ıspanak gibi sebze olarak da tüketilebilmektedir (Lorenz and Coulter 1991; Ahamed et al. 1998; Tan ve Yöndem 2013).

Tahıl ana olarak adlandırılan kinoa son derece besleyicidir. Kinoa tohumu protein, kalsiyum, magnezyum, demir, çinko gibi mineraller, diyet lifi ile $\mathrm{E}$ ve $\mathrm{B}$ grubu vitaminlerince nispeten iyi bir kaynaktır. Ayrıca esansiyel aminoasitlerin tamamını içeren kinoa lisin, sistein ve methionin aminoasitleri açısından da zengin olduğundan çok iyi bir protein kaynağı olarak kabul edilmektedir. Buğday, çavdar, yulaf, darı, mısır ve pirinçten çok daha fazla protein içermektedir. Yağ oranı ise yağlı tohumlardan az ancak tahıllardan daha yüksektir. Kinoa gluten içermediği için glutene duyarlılığı olan çölyak hastaları ve veganların (hayvansal ürün yemeyen) protein ve karbonhidrat intiyaçlarını karşılayan besleyici bir besindir. Bunların yanı sıra kinoa kolesterol de içermemektedir (Tan ve Yöndem 2013; Yıldız et al. 2014; Iglesias-Puig et al. 2015).

\section{Kinoanın kimyasal özellikleri}

Kinoa tohumları yüksek miktarda karbonhidrat, kaliteli protein, yağ, lif, vitamin ve mineral içermektedir. Bu nedenle diğer tahıllarla kıyaslandığında besin değeri daha yüksektir (Çizelge 1) (Ahamed et al. 1998; Vilehe et al. 2003).

Nişasta tahıllarda en önemli karbonhidrat olup, kuru maddenin yaklaşık olarak \% 60-70'ini oluşturmaktadır. Kinoada da \% 58.1-64.2 oranında nişasta bulunmaktadır (RepoCarrasco et al. 2003). Kinoa nişastası, buğday nişastasına göre daha düşük jelatinizasyon entalpisi, daha yüksek viskozite ve su bağlama kapasitesine sahiptir (Elgeti et al. 2014). Ayrıca kinoa nişastasının donma ve retrogradasyonda mükemmel bir stabiliteye sahip olduğu, bu nedenle kimyasal olarak modifiye edilmiş nişastaların yerine kullanılabileceği ifade edilmektedir (Repo-Carrasco et al. 2003).

Kinoada ortalama protein miktarı \% 15 civarında olup, bu miktar buğday, arpa, yulaf, pirinç ve sorgum gibi tahıllardan daha yüksektir. Çözünebilir protein içeriği ise arpaya benzer fakat buğday ve mısırdan daha yüksektir. Kinoa tohumu bütün esansiyel aminoasitleri içermekte olup, bitkisel kaynaklarda az bulunan lisin (\% 5.1-6.4) ve methionin (\% 0.4-1.0) aminoasitlerini yapısında fazla miktarda bulundurmaktadır 
(Chauhan et al. 1992; Ahamed et al. 1998; Abugoch James 2009). Ayrıca kinoa proteinleri, arpa, soya ve buğday proteinlerinden daha fazla histidin amino asidi içermektedir. İçerdiği methionin ve sistein miktarının 2-12 yaş arası çocuklar ve yetişkinler için yeterli olduğu ifade edilmektedir (Abugoch James 2009). Bu nedenle kinoa ununun buğday ununa ilavesi, elde edilen ürünlerin protein kalitesini artırmaktadır (Enriquez et al. 2003).

Kinoa tohumları, yağ oranı yönünden yağ bitkileri ile kıyaslandığında fakir, fakat tahıllara göre daha zengindir. \% 4.5-8.75 oranında yağ içermekte olup, bu yağ oleik asit (\% 24) ve linoleik asit (\% 52) açısından zengindir. Linoleik asit açısından zengin olması tohumun besin değerini artırmaktadır. Kinoa yağı sarımtırak, keskin kokulu, acı ve yakıcı bir aromaya sahiptir. Yağ asidi kompozisyonu açısından buğday lipitleri ile bezer olduğu belirtilmektedir. Çoklu doymamış yağların doymuş yağlara oranının (4.9) soya, mısır, zeytin yağı gibi yağlardan daha yüksek olduğu ifade edilmektedir. Kinoada serbest yağ asidi oranının (\% 18.9) da buğday ve çimlenmiş arpadan daha yüksek olduğu belirtilmektedir (Lorenz and Coulter 1991; Ahamed et al. 1998; Tan ve Yöndem 2013; Iglesias-Puig et al. 2015). Yapılan bir çalışmada kinoa yağında yaklaşık olarak \% 11 oranında doymuş yağ olduğu, doymuş yağ asitleri arasında da palmitik asitin baskın olduğu ifade edilmiştir. Çalışmada kinoa yağında \% 52.3 linoleik asit, \% 23 oleik asit, \% 8.1 linolenik asit ve \% 2'nin altında erusik asit bulunduğu belirlenmiştir (Wood et al. 1993).

Repo-Carrasco et al. (2003) kinoada y-tokoferol oranının $797 \mathrm{ppm}$, $\alpha$-tokoferol oranın ise $721 \mathrm{ppm}$ olduğunu ifade etmişlerdir. Tokoferollerin 4 izomeri antioksidan aktivitlerine

Çizelge 1. Kinoa ve bazı tahılların bazı kimyasal özellikleri (\%) (Repo-Carrasco et al. 2003)

Table 1. Some chemical properties of quinoa and some cereals (\%)

\begin{tabular}{lccccc}
\hline & \multicolumn{1}{c}{ Kinoa } & Buğday & Mısır & Çeltik \\
\cline { 6 - 6 } \cline { 5 - 6 } Protein & 14.4 & 10.5 & & 11.1 & 9.1 \\
Yağ & 6.0 & 2.6 & 4.9 & 2.2 \\
Karbonhidrat & 72.6 & 78.6 & 80.2 & 71.2 \\
Ham lif & 4.0 & 2.5 & 2.1 & 10.2 \\
Kül & 2.9 & 1.8 & 1.7 & 7.2 \\
\hline
\end{tabular}

göre $\delta>\gamma>\beta>\alpha$ şeklinde sıralandıklarından kinoa yağının, $\gamma$-tokoferolün güçlü antioksidan etkisi nedeniyle, raf ömrünün uzun olduğunu belirtmişlerdir.

Kinoa tohumu $\mathrm{Ca}, \mathrm{P}, \mathrm{Mg}, \mathrm{K}, \mathrm{Fe}, \mathrm{Cu}, \mathrm{Mn}$ ve Zn yönünden zengin olup, Na yönünden fakirdir. Özellikle kalsiyum (70-874 mg/100g) ve potasyum (845-1.201 mg/100g) içeriği diğer tahıllara göre oldukça yüksektir (Johnson 1990; Ahamed et al. 1998).

Tahıl olmayan ancak tahılların yerine tüketilen kinoa, riboflavin $(0.2-0.3 \mathrm{mg} / 100 \mathrm{~g})$ ve folik asit $(78.1 \mu \mathrm{g} / 100 \mathrm{~g})$ açısından buğday, arpa, pirinç ve mısırdan daha zengindir. Kinoa tohumlarında saponinin uzaklaştırma işleminin vitamin kompozisyonu minör düzeyde değiştirdiği bildirilmektedir (Ahamed et al. 1998).

Ranhotra et al. (1993) tarafında yapılan bir çalışmada kabuğu soyulmuş kinoada nişasta $\% 58$, protein $\% 15.6$, şeker $\% 2.7$, toplam diyet lifi \% 8.9, yağ \% 4.6, kül \% 2.3 olarak bulunmuştur. Yapılan başka bir çalışmada ise, yıkanmış kinoada un verimi \% 60 iken, pişirilmiş kinoada \% 63.7 olarak bulunmuştur (Repo-Carrasco et al. 2003).

Yüksek besleme değerine rağmen kinoa tohumlarının bileşiminde saponin, proteaz inhibitörleri, fitik asit gibi beslenmeyi olumsuz yönde etkileyen bileşikler de bulunmaktadır (Ahamed et al. 1998).

Kinoada \% 1.0-1.2 oranında bulunan saponinler, acı ve sabunumsu tada sahip olup, ürünün lezzet ve rengini etkileyeceğinden tüketimden önce uzaklaştırılmalıdır. Saponinler tohumun dış kısmında bulunduğundan parlatma ve yıkama ile uzaklaştırılabilmektedir (Chauhan et al. 1992; Reichert et al. 1986; Koziol 1992; Ahamed et al. 1998; Yıldız et al. 2014). Reichert et al. (1986) yaptıkları bir çalışmada aşındırarak kabuk soyma işlemiyle saponin düzeyinin azaltmışlardır. RepoCarrasco-Valencia and Serna (2011) saponinlerin uzaklaştırılması için en yaygın metodun tohumların 8 katı kadar su ile yıkanması olduğunu ifade etmişlerdir. Saponinler sulu çözeltilerde $\% 0.1$ kadar düşük konsantrasyonlarda bile kalıcı köpük oluşturabilmektedirler. Bu nedenle alkolsüz içeceklerde ve bazı gıdalarda kullanılabilmektedir. Başka bir çalışmada ise kinoa tohumlarından saponinlerin uzaklaştırımasının aminoasit kompozisyonu 
üzerine etkisi araştırılmış ve kinoa tohumlarının farklı sıcaklıkta su ile muamele edilmesinin aminoasit kompozisyonunu değiştirmediği görülmüştür. Ancak, biyolojik açıdan protein yeterlilik oranının $85^{\circ} \mathrm{C}$ 'de düştüğü, $70^{\circ} \mathrm{C}$ 'de ise değişmediği ifade edilmiştir (Ahamed et al. 1998). Normal çeşitlere göre düşük miktarda $(1 / 10)$ saponin içeren çeşitler de mevcut olup, bunlar "sweet" olarak isimlendirilmektedir (Gee et al. 1993).

Kinoada bulunan fitik asit buğday ve çavdardan farklı olarak sadece dış katmanlarda değil endospermde de bulunmaktadır. Yapılan bir çalışmada kinoa tohumlarında fitik asit miktarı 10.5-13.5 mg/g olarak bulunmuştur. Fitatlar minerallerle kompleks oluşturarak özellikle çocuklarda yetersiz mineral alımına neden olabilmektedir (Koziol 1992; Ahamed et al. 1998).

Kinoada bulunan proteaz inhibitörlerinin miktarı 50 ppm'in altında olup, bu miktarın yaygın olarak tüketilen tahıllardakinden çok daha düşük olduğu, bu nedenle de önemli olmadığı ifade edilmiştir (Ahamed et al. 1998).

Yapılan bir çalışmada kinoa tohumlarının diyet lifi, fenolik bileşikleri ve antioksidan aktivitesi belirlenmiş ve bulunan sonuçlar ekstürüde edilmiş olanlarla karşılaştırılmıştır. Çalışma sonucunda kinoanın diyet lifi, polifenoller ve diğer antioksidan bileşikler açısından iyi bir kaynak olduğu ve ekstrüzyon işleminin besin değerini artırdığı belirtilmiştir (Repo-Carrascu-Valencia and Serna 2011).

\section{Kinoanın ekmek, kek ve bisküvi üretiminde kullanımı}

Graminaeae ailesinden olmadığından "yalancı tahıl" olarak kabul edilen kinoa, una öğütülerek tahıllar gibi kullanılabilmektedir (Repo-Carrasco-Valencia and Serna 2011). Fakat tahıllar içerisinde sadece gluten proteinlerine sahip olan buğdaydan güçlü, yapışkan, gaz tutabilen bir hamur elde edilebilmektedir. Diğer tahıllarda bulunan proteinler hamur oluşturamadığı için, dünyanın pek çok yerinde buğday unu ile karıştırılarak fırın ürünlerinde kullanılmaktadır (Enriquez et al. 2003).

Kinoanın buğday ununa \% 60 oranına kadar karıştırılarak yüksek proteinli kek, kurabiye ve bisküvi üretilebileceği belirtilmektedir. Böylece hem besin değeri artırılmakta hem de kabul edilebilir aromaya sahip ürünler elde edilmektedir. Yapısında gluten bulunmaması kinoanın doğrudan ekmek yapımında kullanımını sınırlandırmaktadır (Ahamed et al. 1998; Vilehe et al. 2003). Repo-Carrasco et al. (2003) kinoa ununun, ekmek yapımında \% 20, pastacılık ürünlerinde ise $\% 50$ oranlarında kullanılabileceğini belirtmişlerdir.

Literatürde kinoanın ekmek, kek, bisküvi gibi ürünlerde kullanımı ile ilgili çeşitli çalışmalar yapılmış ve kinoa ununun kalite ve duyusal özellikler üzerine etkileri ortaya konmaya çalışılmıştır. Lorenz and Coulter (1991) tarafından yapılan bir çalışmada buğday ununa $\% 5,10,20$ ve 30 oranında kinoa unu karıştırılmasının fırın ürünlerine etkisi araştırılmıştır. Buna göre $\% 5$ ve $\% 10$ kinoa unu katkılı ekmeklerin kalitesinin iyi olduğu, kinoa oranı arttıkça ekmeklerin hacimlerinin düştüğü, ekmek içi gözenek yapısının açık olduğu ve tekstürün sertleştiği, $\% 30$ oranında ise tatta acılaşma görüldüğü ifade edilmiştir. Keklerde ise $\% 5$ ve \% 10 kinoa katkısının kabul edilebilir olduğu, katkı oranı arttıkça keklerin yumuşaklığının azaldığı görülmüştür. Çalışmada ayrıca bisküvi de yapılmış ve elde edilen bisküvilerde yayılma oranı düşmüş ancak aroma \% 20'ye kadar olan kinoa unu katkısı ile gelişmiştir. Çalışmada ayrıca bisküvilerin yayılma oranı ve görünüşünün $\% 2$ oranında lesitin katkısı ile iyileştiği belirtilmiştir.

Morita et al. (2001) sert buğday unu ile \% $5,7.5,10,15$ ve 20 oranlarında kinoa unu katkılı ekmekler yapmışlar, \% 7.5 ve $\% 10$ katkılı olan ekmeklerin hacimlerinin arttığını, bu durumun kinoa ununun nişasta, protein ve lipit dengesini geliştirmesinden kaynaklandığını belirtmişlerdir. Ancak \% 15 'den fazla kinoa unu katıldığında hacimde düşüş meydana gelmiştir. Ayrıca katılan kinoa unu miktarı ile orantılı olarak ekmek içi sertliği de artmıştır. Kinoa unu lipaz enzimi ile kombine edildiğinde ise monogliseritlerin serbest hale geçmesi ile depolama sırasında ekmeğin yumuşak kalması sağlanmıştır. Ayrıca jelatinizasyon sıcaklığı ve entalpisinde artış, farinogram değerlerinde ise düşüş görülmüştür.

Buğday ununa \% 5, 10 ve 15 oranlarında kinoa unu karıştırılmasının ekmeklik özellikler üzerine etkisinin belirlendiği başka bir çalışmada, kinoa unu oranı artıkça daha kuvvetli ve uzama kabiliyeti daha az hamurlar elde edilmiştir. Ayrıca kinoa katkısının yaş ve 
kuru gluten ile gluten indeks değerlerini, farinogram özelliklerinden gelişme süresi ve stabilite değerini düşürdüğü bulunmuştur. Çalışma sonunda \% 5 ve \% 10 kinoa unu katkısının ekmek üretimine uygun olduğu, bu ekmeklerin hacimlerinin \% 100 buğday unu ile yapılanlarla aynı olduğu belirtilmiştir (Enriquez et al. 2003).

Hamur reolojik özellikleri ve ekmek özellikleri üzerine yapılan bir çalışmada ise buğday ununa $\% 0,10,20$ ve 30 oranlarında kinoa unu katılmıştır. Farinogram özelliklerinden su absorpsiyonunda önemli bir değişiklik görülmezken, kinoa unu oranı artıkça gelişme süresi ve stabilite değerinde düşüş görülmüştür. Ekstensogram özelliklerinde ise enerji değeri düşmüştür. Sonuçta elde edilen ekmeklerin hacimleri de düşmüş olup, $\% 30$ katkılı ekmeklerin hacimleri katkısız olanların ancak \% 66' sı kadar bulunmuştur (Svec et al. 2011).

Wang et al. (2015) tarafından farklı oranlarda kinoa ve buğday unu kullanılarak, ekmek ve bisküvi yapılmıştır. Elde edilen ürünlerin spesifik hacmi düşmüş, buna karşın yoğunluk, sertlik, çiğnenebilirdik, renk özelliklerinden de koyuluk, kırmızılık ve sarılık değerleri artmıştır. Buğday ununda yüksek molekül ağırlıklı proteinlerin, kinoa ununda ise düşük molekül ağırlıklı proteinlerin fazla miktarda olduğu ve yüksek molekül ağırlıklı proteinler ile büyük ekmek hacmi arasında pozitif bir korelasyon olduğu ifade edilmiştir. Ayrıca kinoa unu ilavesi ile buğday unundaki glutenin de seyrelmiş, ve bunun da ekmek hacmini düşürebileceği belirtilmiştir. Kinoa unu içeren ekmeklerin küflenmeye karşı daha az hassas olduğu da görülmüştür.

Kinoa yüksek $\alpha$-amilaz aktivitesine sahip olduğundan, nişastayı parçalayarak fermente olabilir şeker miktarını artırmakta ve bu da ekmek hacmini artırmaktadır. Fakat kinoa oranı arttıkça gluten oranı azalmakta ve ekmek hacmi düşmektedir (Ahamed et al. 1998).

Iglesias-Puig et al. (2015), tam kinoa ununun ekmek özellikleri üzerine etkisi ve besleyici bileşen olarak kullanılabilirliğini araştırmışlardır. Çalışmada kinoanın kaliteyi düşürdüğünü, ancak besin değerini arttırdığını bulmuşlardır. Kinoanın diyet lif, mineral, protein, yüksek biyolojik değer ve sağlıklı yağ içeriğinden dolayı ekmek yapımında $\% 25$ oranında kullanılabileceğini ifade etmişlerdir.
Kinoada bulunan fonksiyonel bileşikler, onun çeşitli ürünlerde kullanımı açısından üstünlük sağlamaktadır. Örneğin kinoa ununda bulunan polifenoller, fırın ürünlerinin antioksidan kapasitesini artırmaktadır. Ayrıca, ekmeğe katıldığında kinoda bulunan linoleik asitin, doymuş yağ miktarını renk ve tekstüre zarar vermeden düşürdüğü ifade edilmiştir (Wang et al. 2015). Chłopicka et al. (2012) tarafından yapılan bir çalışmada buğday ununa $\% 15$ ve $\% 30$ oranlarında kinoa unu katılmış ve çalışma sonucunda unlardaki toplam flavonoid miktarı, ekmeğe göre 2-4 kat daha fazla çıkmıştır. Fakat, kinoa karışımlı undan elde edilen son üründeki toplam flavonoid miktarı, buğdayınkine göre oldukça fazla çıkmıştır. Ayrıca, \% 15 oranına kıyasla $\% 30$ oranından daha yüksek antiokasidan aktivite değeri elde edilmiştir.

Kinoanın gluten içermemesi onun çölyak hastaları tarafından tüketilebilmesine de olanak sağlamaktadır (Repo-CarrascuValencia and Serna 2011). Fakat gluten içermeyen ürünlerin kalitesinin ve besin değerinin düşük olduğu belirtilmektedir. Elgeti et al. (2014) tarafından yapılan bir çalışmada beyaz kinoa unu kullanımı ile glutensiz ekmeklerin kalitesinin geliştirilebileceği ifade edilmiştir. Başka bir çalışmada ise kavrulmuş ve kavrulmamış kinoa ununun glutensiz kek üzerine etkisi araştırımıştır. Çalışma sonucunda kavrulmamış kinoa ununun, kavrulmuş olanlara göre duyusal özelliklere daha olumlu etki ettiği görülmüştür (Rothschild et al. 2015).

\section{Sonuç}

Kinoa yapısında gluten proteinlerini içermediğinden, buğday ununa belli oranlarda katılarak yüksek proteinli ekmek, kek ve bisküvi gibi fırın ürünlerinin üretiminde kullanılmaktadır. Böylece hem besin değeri artırılmakta hem de kabul edilebilir aromaya sahip ürünler elde edilmektedir. Ayrıca, çölyak hastalarının kullanabileceği alternatif bir bitki konumundadır. Bu nedenle dünyada tarımı ve kullanımı giderek yaygınlaşmaktadır. Son yıllarda ülkemizde de tanınmaya ve üzerinde çalışılmaya başlanmıştır. Fakat çalışmalar yok denecek kadar azdır. Bu nedenle kinoanın hem yetiştiricilik koşullarının hem de farklı ürünlerde kullanılabilme olanaklarının araştırımasında fayda vardır. 


\section{Açıklama}

$\mathrm{Bu}$ çalışma Nevşehir'de 28-30 Nisan 2015 tarihleri arasında İç Anadolu Bölgesi 2. Tarım ve Gıda Kongresinde poster bildiri olarak sunulmuş ve özet, bildiri kitabında yer almıştır.

\section{Kaynaklar}

Abugoch James L.E., 2009. Quinoa (Chenopodium quinoa Willd.): Composition, chemistry, nutriti onal, and functional properties. (Ed: LT Steve), Advances in Food and Nutrition Research. Academic Press, New York, pp. 131

Ahamed N.T., Singhal R.S., Kulkarni P.R. and Pal M., 1998. A lesser-known grain, Chenopodium quinoa: Review of the chemical composition of its edible parts. Food and Nutrition Bulletin, 19(1):61-70

Anonim, 2015. Türkiye İstatistik Kurumu (TÜiK). http://www.tuik.gov.tr (Erişim tarihi: 07.10.2015)

Chauhan G.S., Eskin N.A.M. and Tkachuk R., 1992. Nutritients and antinutritients in quinoa seed. Cereal Chemistry, 69(1):85-88

Chłopicka J., Pasko P., Gorinstein S., Jedryas A. and Zagrodzki P., 2012. Total phenolic and total flavonoid content, antioxidant activity and sensory evaluation of pseudocereal breads. Food Science and Technology, 246:548-555

Elgeti D., Nordlohne S.D., Föste M., Besl M., Linden M.H., Heinz V., Jekle M. and Becker, T., 2014. Volume and texture improvement of glutenfree bread using quinoa white flour. Journal of Cereal Science, 59(1):41-47

Enriquez N., Peltzer M., Raimundi A., Tosi V. and Pollio M.L., 2003. Characterization of wheat and quinoa flour in relation to their breadmaking quality. The Journal of the Argentine Chemical Society, 91(4-6):47-54

Gee J.M., Price K.R., Ridout C.L., Wortley G.M., Hurrell R.F. and Johnson I.T., 1993. Saponins of quinoa (Chenopodium quinoa): Effects of processing on their abundance in quinoa products and their biological effects on intestinal mucosaltissue. J. Sci. Food Agric., 63:201-209

Iglesias-Puig E., Monederob V. and Haros M., 2015. Bread with whole quinoa flour and bifidobacterial phytases increases dietary mineral intake and bioavailability. LWT - Food Science and Technology, 60(1):71-77

Jacobsen S.E., 2003. The worldwide potential for quinoa (Chenopodium quinoa Willd.). Food Rev. Int., 19:167-177
Johnson D.L., 1990. New grains and pseudograins (Ed: J Janick and E. Simon), Advances in new crops. Timber Press, Portland, OR, pp. 122127

Karyotis T., Iliadis C., Noulas C. and Mitsibonas T., 2003. Preliminary research on seed production and nutrient content for certain quinoa varieties in a saline-sodic. Soil J. Agron. Crop Sci., 189:402-408

Koziol M.J., 1992. Chemical composition and nutritional evaluation of quinoa (Chenopodium quinoa Wild.). Journal of Food Composition Analysis, 5:35-68

Lindeboom N., 2005. Studies on the characterization, biosynthesis and isolation of starch and protein from quinoa (Chenopodium quinoa Willd.). Ph. D. Thesis, University of Saskatchewan, Canada

Lorenz K. and Coluter L., 1991. Quinoa flour in baked products. Plant Foods Human Nutrition, 41(3):213-223

Morita N., Hirata C., Park S.H. and Mitsunaga T., 2001. Quinoa flour as a new foodstuff for improving dough and bread. Journal of Applied Glycoscience, 48(3):263-270

Ranhotra G.S., Gelroth J.A., Glaser B.K., Lorenz K.J. and Johnson D.L., 1993. Composition and protein nutritional quality of quinoa. Cereal Chemistry, 70(3):303-305

Reichert R.D., Tatarynovich J.T. and Tyler R.T., 1986. Abrasive dehulling of quinoa (Chenepodium quinoa): Effect on saponin content as determined by an adapted hemolytic assay. Cereal Chem., 63(6):471475

Repo-Carrasco R. Espinoza C. and Jacobsen S.E., 2003. Nutritional value and use of the Andean crops quinoa (Chenopodium quinoa) and kaniwa (Chenopodium pallidicaule). Food Reviews International, 19(1\&2):179189

Repo-Carrasco-Valencia R. and Serna L.A., 2011. Quinoa (Chenopodium quinoa, Willd.) as a source of dietary fiber and other functional components. Ciencia e Technologia de Alimentos, 31(1):225-230

Rothschild J., Rosentrater K.A., Onwulata C., Singh M., Menutti L., Jambazian P. and Omary M.B., 2015. Influence of quinoa roasting on sensory and physicochemical properties of allergen-free, gluten-free cakes. International Journal of Food Science and Technology, 50:1873-1881 
Svec I., Hruskova M., Hofmanova T. and Vitova M., 2011. Quinoa - Wholemeal flour for cereal products. Proceedings of the $6^{\text {th }}$ CIGR Section VI International Symposium "Towards a Sustainable Food Chain" Food Process, Bioprocessing and Food Quality Management. April 18-20, 2011. Nantes, France, p. 1-4

Tan M. ve Yöndem Z., 2013. İnsan ve hayvan beslenmesinde yeni bir bitki: Kinoa (Chenopodium quinoa Willd.). Alınteri Zirai Bilimler Dergisi, 25(2):62-66

Vilehe C., Gely M. and Santalla E., 2003. Physical properties of quinoa seeds. Biosystems Engineering, 86 (1):59-65
Wang S., Opassathavorn A. and Zhu F., 2015 Characteristics of cookie, bread and Chinese steamed bread. Journal of Texture Studies, 46:281-292

Wood S.G., Lawson L.D., Fairbanks D.J., Robison L.R. and Andersen W.R., 1993. Seed lipid content and fatty acid composition of three quinoa. Journal of Food Compozition and Analysis, 6(1):41-44

Yıldız M., Tansı S. and Sezen S.M., 2014. New plants with commercial potent. Turkish Journal of Agricultural and Natural Sciences, Special Issue 1:1036-1042 